International Review of Research in Open and Distributed Learning Volume 19, Number 4

\title{
Critical Factors of the Adoption of e-Textbooks: A Comparison Between Experienced and Inexperienced Users
}

Wei-Hsi Hung', Pei-Hsuan Hsieh², and Yao-De Huang ${ }^{3}$

${ }^{1}$ National Chengchi University, Taiwan, R.O.C., ${ }^{2}$ National Cheng Kung University, Taiwan, R.O.C., ${ }^{3}$ National Chung Cheng University, Taiwan, R.O.C.

\begin{abstract}
The use of e-textbooks has become popular in certain countries, yet there is debate in the literature about whether it is advantageous to adopt e-textbooks and if they positively influence students' learning and performance. Prior studies on the acceptance of e-textbooks were mainly based on one theoretical perspective, and did not differentiate samples between experienced and inexperienced users. From a social- and task-related view, this study aims to identify the critical factors that stimulate acceptance intentions of e-textbooks among tertiary students, particularly between experienced and inexperienced users. Based on 912 questionnaires, this study found that performance expectancy, perceived enjoyment, and perceived task-technology fit are the factors affecting students' behavioral intention for acceptance in both sampling groups. However, social impact only has significant influence on acceptance intention of inexperienced users. Also, gender has a moderating effect on the relationship of performance expectancy and behavioral intention of inexperienced users only. This study provides useful implications for marketing e-textbooks, and fills the literature gap.
\end{abstract}

Keywords: e-textbooks, technology acceptance, perceived task-technology fit, higher education, perceived cost 


\section{Introduction}

E-textbooks are defined as the digital content which is developed for teaching and learning purposes in higher education, and which can be read from various types of electronic devices (e.g., laptops and electronic readers). E-textbooks are different from e-books, because they are used for studying a subject that is usually part of a course. There is debate in the literature about whether it is advantageous to adopt e-textbooks and if they positively influence students' learning performance (Baker, Al-Gahtani, \& Hubona, 2010; Dennis, Abaci, Morrone, Plaskoff, \& McNamara, 2016; Fischer, Hilton, Robinson, \& Wiley, 2015). Many students find e-textbooks difficult to access and navigate. Also, working on an Internet-enabled device can add potential distractions, such as checking instant messages and visiting non-study related websites. These reasons may explain why the adoption of e-textbooks is still in beginning stages in some countries, although the technology is not a barrier to use e-textbooks. Most of the studies which have investigated students' perceptions of using e-textbooks only implied experiments to determine willingness to replace traditional paper books with e-textbooks (Woody, Daniel, \& Baker, 2010). The literature lacks of research that can explain the acceptance of e-textbooks from the social and task perspectives.

In order to fill this gap, this study aims to identify critical factors that affect user acceptance and utilization of e-textbooks from both social and task perspectives. In terms of social perspective, this study adopts Venkatesh, Morris, Davis, and Davis' (2003) unified theory of acceptance and use of technology (UTAUT) to identify key factors of adopting e-textbooks. The UTAUT integrates various models of technology acceptance that consider both gender and user experience as significant moderating factors for their intention to adopt new technologies. However, the results regarding the moderating effect of gender are, apparently, unstable among the various studies which have been conducted in different contexts. Accordingly, the causal relationship between gender and user experience needs further testing, particularly concerning the user acceptance of e-textbooks.

In terms of task perspective, this study adopts the perceived task-technology fit (PTTF) concept to study the fit among individuals' feelings, the technology itself, and task requirements. Marcolin, Compeau, Munro, and Huff (2000) incorporated individual characteristics into a task-technology fit (TTF) model (Goodhue \& Thompson, 1995), because an individual's perception is critical in utilizing the technology and performing tasks, and so influences an individual's perception of fit. In order to achieve the research objectives, a model based on combining the factors in the UTAUT and PTTF models is proposed for testing, in conjunction with two moderating factors, that is gender and experience. A survey of tertiary (college and university) students in Taiwan was conducted to verify the proposed model.

\section{Literature Review}

\section{Adoption of e-Textbooks}

The topic of e-books has been studied frequently in recent years. Yet, research on the acceptance of etextbooks has received less attention, relatively. Most of the studies are from education-related journals, 
in which the technology acceptance model is considered the favorite theoretical model. Perceived ease of use and perceived usefulness are significant factors influencing users' acceptance (Al-Ali \& Ahmed, 2015; Gu, Wu, \& Xu, 2015; Hsiao, Tang, \& Lin, 2015; Johnston, Berg, Pillon, \& Williams, 2015; Ngafeeson \& Sun, 2015; Stone \& Baker-Eveleth, 2013). The review of the literature shows that more attention should be paid to students' perceptions of e-textbook acceptance from a more diversified view, particularly from the social perspective, in order to better explain the adoption of such technology.

\section{Unified Theory of Acceptance and Use of Technology}

Venkatesh et al. (2003) proposed a model, the UTAUT that integrates eight prior models into its theoretical basis to better explain the acceptance of information systems or technologies. The model contains four main dimensions, namely performance expectancy (PE), effort expectancy (EE), social influence (SI), and facilitating conditions (FC), which are further subject to the moderating effects from gender, age, experience, and voluntary use. Venkatesh et al. (2003) claimed that the UTAUT can explain more than $70 \%$ of the intentions for using different technologies, and that the theory represents a more extensive and complete model for acceptance research. The UTAUT has gained increased attention from researchers recently (e.g., Isa \& Wong, 2015; Kaba \& Touré, 2014; Kohnke, Cole, \& Bush, 2014). Venkatesh, Thong, and Xu (2012) have extended the UTAUT by adding hedonic, habit, and price value factors, which is occasionally named UTAUT2. However, habit is not suitable. Moreover, utilizing etextbooks, on the other hand, is more likely for achieving learning tasks in the classroom, rather than for amusement purpose. Thus, this study chose the original UTAUT model, rather than UTAUT2, for the basis of research model.

\section{Perceived Task-Technology Fit Theory}

Goodhue and Thompson (1995), based on Vessey's (1991) cognitive fit model, proposed the TTF theory to explain the best fit between information technology (IT) and personal tasks. The TTF theory includes five variables: Technology characteristics, task characteristics, individual performance, TTF, and system utilization. Marcolin et al. (2000) linked personal characteristics with TTF, and argued that individuals' characteristics and perceptions are necessary elements for measuring TTF. Thus, the PTTF is suitable for determining the relationships between attitudes toward the technological abilities and task requirements, as well as user capabilities (Kuo, 2011; Shin, Chung, Hart, Joun, \& Koo, 2015).

\section{Unified Theory of Acceptance and Use of Technology, and Perceived Task-Technology Fit Theory}

While the UTAUT arguably has broader coverage, the model fails to account for the nature of tasks that the TTF theory explains. Recently, Gerhart, Peak, and Prybutok (2015) also suggested a positive fit exists between the UTAUT and TTF models. Accordingly, the integration of the UTAUT and TTF for developing an alternative model seems appropriate for studying technology acceptance. In recent years, several studies have adopted the concepts of both the UTAUT and TTF in researching models to investigate the factors that impact user intentions to adopt customer relationship management, mobile banking, and mobile search (e.g., Pai \& Tu, 2011; Zhou, Lu, \& Wang, 2010). To date, several studies have combined the 
UTAUT and TTF in their models. Since an integrated approach with these two models can overcome their respective shortcomings, this study followed this tendency to clarify tertiary students' intentions toward using e-textbooks. Based on the literature, the antecedents which impact the acceptance intentions should be chosen purposely for the researches in various technologies and various contexts.

\section{Methodology}

\section{The Research Model}

This research proposes a model to further explore user intentions, based on the theoretical models including the UTAUT and TTF (see Figure 1). The factor, age, was in the UTAUT model, but it is excluded here because the students in tertiary level have limited variance in age.

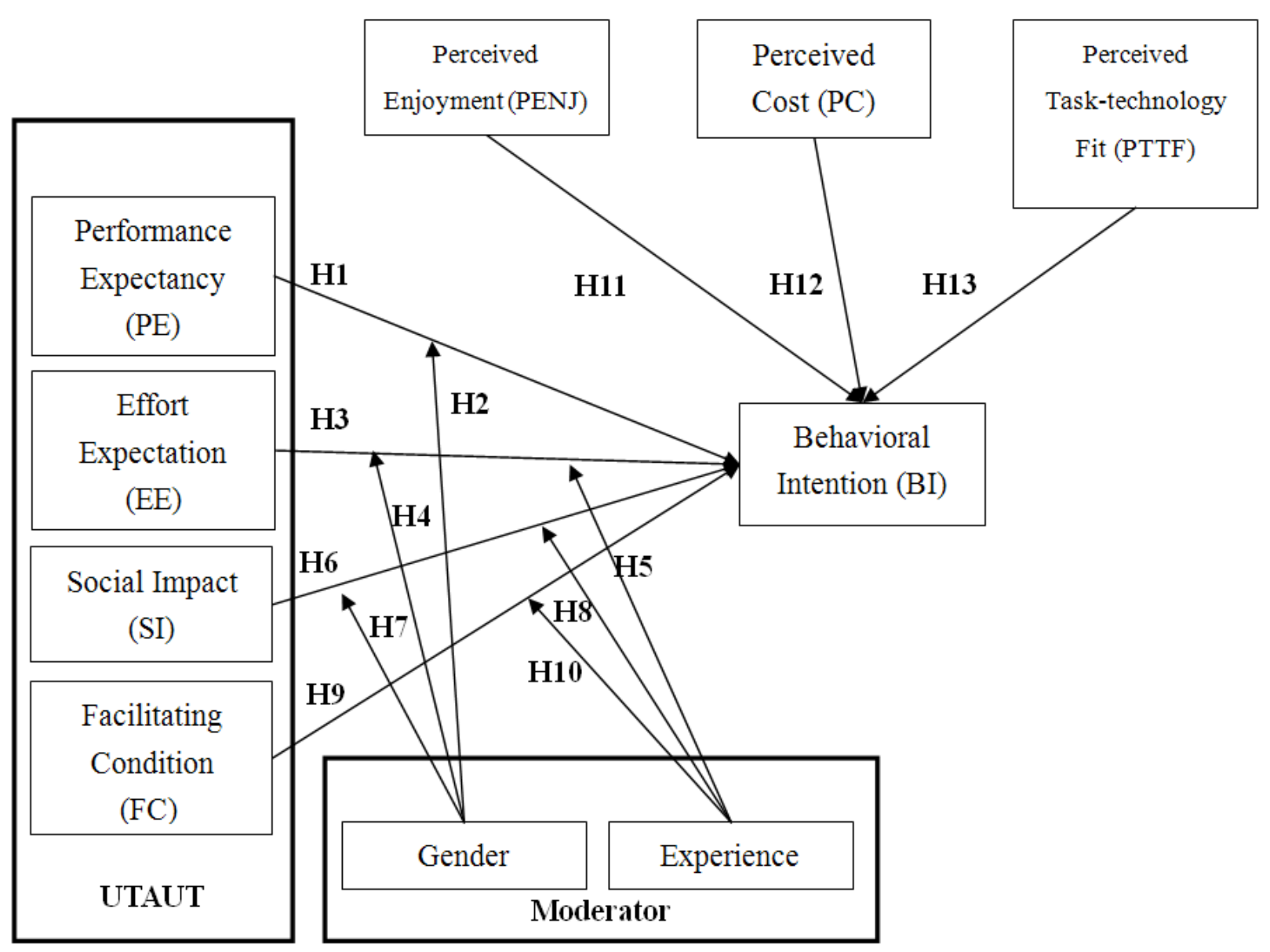

Figure 1. The research model. 
$\mathrm{PE}$ is one of the most influential antecedents of intention to use IT (Venkatesh et al., 2003). Numerous studies have also identified that using IT can enhance high performance and create positive feelings (Bruner \& Kumar, 2005; Moon \& Kim, 2001; Venkatesh et al., 2003). E-textbooks can facilitate learning by offering keyword search functions, and dividing contents into sections, such as interactive maps and charts, to improve students' retention and learning performance (Maynard \& Cheyne, 2005; Young, 2001). Previous studies showed that gender can serve as a moderating variable affecting expectancy and acceptance intention (e.g., Venkatesh et al., 2003; Venkatesh \& Morris, 2000), whereby gender affects the impact of $\mathrm{PE}$ on intention in computer-oriented environments, especially for males. Accordingly, this study proposes the following two hypotheses:

H1: PE has significant and positive effects on tertiary students' behavioral intentions (BIs) for using e-textbooks.

H2: The moderating variable, gender, affects PE of tertiary students' BIs for using e-textbooks.

Prior studies indicated that EE was a strong determent for personal intentions (Venkatesh \& Morris, 2000; Venkatesh, Morris, \& Ackerman, 2000), with this factor having been discussed frequently at the early stage of new-technology acceptance, such as for smart devices (Davis, 1989; Venkatesh \& Davis, 2000; Szajna, 1996). Past studies indicated that students' preferences and interactions with textbooks were associated with previous experiences (Clough, Jones, McAndrew, \& Scanlon, 2008). Thus, prior experience can enhance the acceptance of new technology, while reducing the anxiety and difficulties of adoption (Clough et al., 2008). Venkatesh et al. (2003) suggested that, in addition to experience, gender can also affect the impact of EE on intention. Furthermore, this effect is more apparent with women, particularly when they lack technological experience. Adding to this, Gurung and Daniel's (2005) study on e-books also found that the adoption process would proceed more smoothly when a user had relevant experience. Thus, the following hypotheses are proposed:

H3: EE has a significant and positive effect on tertiary students' BI for using e-textbooks.

H4: The moderating variable, gender, influences EE of tertiary students' BI for using e-textbooks.

H5: The moderating variable, experience, influences EE of tertiary students' BI for using etextbooks.

In the scenario where the UTAUT model is applied for, the participants were all in the same social circle (Venkatesh et al., 2003), which means that peers and social groups can influence user adoption of certain technologies, such as e-textbooks and mobile phones. Since users of technologies are in the same social environment, others within that group can be a source of influence. While this aspect is likely to affect etextbooks' users, they may belong to more than one social circle. For example, students interact with each other in the class, but they may interact with their family members or friends outside of school. Previous studies suggested that users are most influenced by those closest to them (Agarwal \& Prasad, 1997; Karahanna, Straub, \& Chervany, 1999; Venkatesh et al., 2003). Thus, social impact becomes a significant 
dimension when studying an individual's intention to use a new technology (Harrison, Mykytyn, \& Riemenschneider, 1997; Mathieson, 1991; Moore \& Benbasat, 1991; Thompson, Higgins, \& Howell, 1991; Venkatesh \& Davis, 2000), such as exploring students' intentions to use e-textbooks. Moreover, gender and experience are two moderating variables that may adjust the influence of social impact on intentions (Venkatesh et al., 2003; Venkatesh \& Morris, 2000). Based on the above discussions, three hypotheses are proposed:

H6: Social impact has a significant and positive effect on tertiary students' BI for using etextbooks.

H7: The moderating variable, gender, influences the social impact on tertiary students' BI for using e-textbooks.

H8: The moderating variable, experience, influences the social impact on tertiary students' BI for using e-textbooks.

Venkatesh et al. (2003) discovered that, when both effort and PE appear in the model of personal computer utilization and the innovation diffusion theory model as antecedent variables, FC (the supports received for using e-textbooks) have no effect on intention. However, if EE is excluded from the theory of planned behavior or the decomposed theory of planned behavior models, then the FC becomes a predictor of intention. Therefore, Venkatesh et al. (2003) argued, for the UTAUT model, FC are not influential on the intention to use a technology. In researching Computer Aided Software Engineering, Dasgupta, Haddad, Weiss, and Bermudez (2007) found that FC had no effect on intentions. Other prior studies, in their research contexts, have verified the same result (Amoroso \& Hunsinger, 2009; Liu \& Tsai, 2011).

However, the literature indicates that users' Internet experiences can significantly moderate facilitation of user intentions; those displaying neuroticism are especially vulnerable and need to find security (Wang \& Yang, 2005). Venkatesh Brown, Maruping, and Bala (2008) discussed this in terms of duration, frequency, and intensity, and found that intention is a better predictor of behavior for extended periods of use. Experienced users are likely to have formed habits for using a system, and thus their intentions become an automatic behavior (Venkatesh, Thong, \& Xu, 2012). Based on the literature, the following hypotheses are proposed:

H9: FC have no effect on tertiary students' BI for using e-textbooks.

H10: The moderating variable, experience, influences FC on tertiary students' BI for using etextbooks.

Previous studies have indicated that perceived enjoyment (PENJ) affects the use of technology (Agarwal \& Karahanna, 2000; Chung \& Tan, 2004; Davis, Bagozzi, \& Warshaw, 1992). In Van der Heijden's (2004) study, PENJ represented a strong factor for intention, and was reported to be even stronger than perceived usefulness. As Venkatesh et al. (2003) stated, if computer users have intrinsic motivation, they 
will then feel more comfortable with utilizing the new technology because their interest overcomes their negative feelings of spending extra effort. In other words, if an individual finds e-textbooks fun and pleasant to use, the inclination to use them would be stronger (Lai \& Ulhas, 2012; Maynard \& Cheyne, 2005; Van der Heijden, 2004). Contrarily, for those who do not feel at ease in their use, a strong use intention may not exist. Based on the findings arising from the literature and the results of prior studies, the following hypothesis is proposed:

H11: PENJ has a significant and positive effect on tertiary students' BI for using e-textbooks.

Chen and Hitt (2002) indicated that, when users switch to different products or services, they incur additional costs, such as equipment, access, and transmission costs. Researchers have suggested that new technology and service providers should search methods for reducing these costs to promote acceptance (Young, 2001). Currently, e-textbooks confront a user-transition situation, because users have other similar and familiar means to obtain the required information (Lai \& Ulhas, 2012; Van der Heijden, 2004). Recent studies have shown that perceived cost is an influential factor that can create a negative impact on adoption intention (e.g., Boroughs, 2010; Wu \& Wang, 2005). Therefore, the following hypothesis is proposed:

H12: Perceived cost has a significant negative effect on tertiary students' BI for using e-textbooks.

Users' intentions increase when they perceive a high degree of TTF; contrarily, perceiving a relatively low degree of TTF decreases users' intentions (Lee, Cheung, \& Chen, 2005; Lin \& Huang, 2008). As previous studies identified, when users adopt a new technology, the TTF produces significant influences. Lin and Huang (2008) discovered that the PTTF affects an individual's intention to use the knowledge management system. In this study, despite the fact that e-textbooks have many advantages, such as ease of transport and multimedia, if these advantages are not sufficiently helpful for the user's task, etextbooks may not be an alternative to traditional textbooks. Thus, a final hypothesis is proposed:

H13: PTTF has a significant effect on the positive BI of tertiary students' toward the use of etextbooks.

\section{Questionnaire Design}

A questionnaire was designed for testing the proposed research model, and a 5-point Likert scale was employed for the response. In order to avoid unreliable data produced from participants' carelessness or rushed responses, the questionnaire included several reverse questions. Three information systems academics and two industrial experts helped revisions of the questionnaire, specifically for correcting semantic errors and checking completeness of the questions, to ensure the overall design was valid and clear, and the questions were appropriate and representative.

\section{Data Collection and Analysis}

In order to study higher education students and their intentions toward using e-textbooks, this research invited students who were enrolled in tertiary studies (either colleges or universities) in Taiwan to 
participate. The participants included both graduate and undergraduate students. The final version of the completed questionnaire was distributed via websites and major forums in Taiwan. The distribution period was one month. After receiving the completed questionnaires, several functions of the statistical software, SPSS, were utilized to perform descriptive analysis, factor analysis, reliability and validity tests, and model verification.

\section{Results and Discussions}

\section{Participants}

A total of 1,140 questionnaires were collected. After eliminating invalid questionnaires, 912 valid ones remained, including 396 experienced users (had used the e-textbook) and 516 inexperienced users (had never used the e-textbook). For the 396 experienced users, most 235 (58.7\%) were male and 161 (41.3\%) were female. For the 516 inexperienced users, 311 (60.3\%) were male and 205 (39.7\%) were female. In terms of the participants' experience with e-textbooks, 220 (55.6\%) subjects had less than one year's experience.

\section{Reliability and Validity Testing}

In terms of reliability, the composite reliability values of the models for exploring the inexperienced users' and experienced users' intentions were both over 0.7, indicating that each variable in both models reached an acceptable level of reliability. This study adopted the principal component analysis to test construct validity, and measured the factor loadings to determine if the questionnaire achieved both discriminant and convergent validities. According to Hair, Black, Babin, and Anderson (2010), when the number of samples surpasses 150, a factor loading over 0.45 achieves construct validity. This study used the varimax and equamaz of the orthogonal rotation method to perform adjustments in the factor analysis.

In terms of both experienced and inexperienced users, after conducting the factor analysis, this study deleted four questions. After the deletions, the FC construct had less than three items, resulting in deletion of the entire construct. The factor analysis results show that all items converged in the corresponding constructs, and that each construct was significantly different from the others. The factor loading values which the researchers obtained were all greater than 0.45 , which indicates good construct validity. This study also tested the correlations among constructs via Pearson correlation analysis; Table 1 shows the results.

Table 1

Correlation Analysis

\begin{tabular}{ccccccccc}
\hline & PE & EE & SI & FC & PTTF & PENJ & PC & BI \\
\hline PE & 1 & $0.509^{* * *}$ & $0.568^{* * *}$ & NA & $0.764^{* *}$ & $0.610^{* * *}$ & -0.072 & $0.671^{* *}$ \\
EE & $0.464^{* *}$ & 1 & $0.339^{* *}$ & NA & $0.633^{* *}$ & $0.513^{* *}$ & -0.003 & $0.458^{* *}$
\end{tabular}




\begin{tabular}{ccccccccc} 
SI & $0.549^{* *}$ & $0.192^{* * *}$ & 1 & - & $0.524^{* *}$ & $0.401^{* *}$ & -0.078 & $0.484^{* *}$ \\
FC & $0.385^{* *}$ & $0.450^{* *}$ & $0.293^{* *}$ & 1 & $\mathrm{NA}$ & $\mathrm{NA}$ & $\mathrm{NA}$ & $\mathrm{NA}$ \\
PTTF & $0.716^{* * *}$ & $0.532^{* * *}$ & $0.508^{* *}$ & $0.516^{* *}$ & 1 & $0.683^{* *}$ & $-0.097^{*}$ & $0.664^{* *}$ \\
PENJ & $0.571^{* *}$ & $0.509^{* *}$ & $0.347^{* *}$ & $0.393^{* *}$ & $0.664^{* *}$ & 1 & -0.001 & $0.616^{* *}$ \\
PC & -0.027 & -0.059 & 0.048 & $-0.204^{* *}$ & -0.025 & 0.075 & 1 & $-0.143^{* *}$ \\
BI & $0.622^{* *}$ & $0.415^{* * *}$ & $0.370^{* *}$ & $0.394^{* * *}$ & $0.607^{* *}$ & $0.551^{* *}$ & -0.073 & 1 \\
\hline
\end{tabular}

${ }^{*} \mathrm{P}<0.05{ }^{* *} \mathrm{P}<0.01{ }^{* * *} \mathrm{P}<0.001$.

Note. Experienced users - numbers appear bottom left area of the table; inexperienced users - numbers appear top right area of the table.

\section{Path Analysis Results}

For the participants with experience of using e-textbooks, this study found that four (PE, PENJ, PTTF, and FC) out of seven independent variables have significant and predictive power on BI. These four and the dependent variable (i.e., BI) share 0.685 for the multiple correlation coefficient, 0.469 for the determination coefficient, and 86.454 ( $\mathrm{p}=0.000$; <0.05) for the $\mathrm{F}$ value of the model's overall testing. Figure 2 presents the path analysis results of the participants with experience of using e-textbooks.



Figure 2. Path analysis of experienced users.

For the participants without experience of using e-textbooks, they do not have sense of how the etextbooks provide FC. Thus, FC is not applicable in the model of inexperienced users. This study found 
that five (PE, PENJ, PTTF, PC, and SI) out of seven independent variables have significant predictive power on BI. These five predictors and the dependent variable (i.e., BI) share 0.744 for the multiple correlation coefficient, 0.553 for the determination coefficient, and $126.124(\mathrm{p}=0.000$; <0.05) for the $\mathrm{F}$ value of the model's overall testing. Figure 3 offers the path analysis results of the participants without experience using e-textbooks.

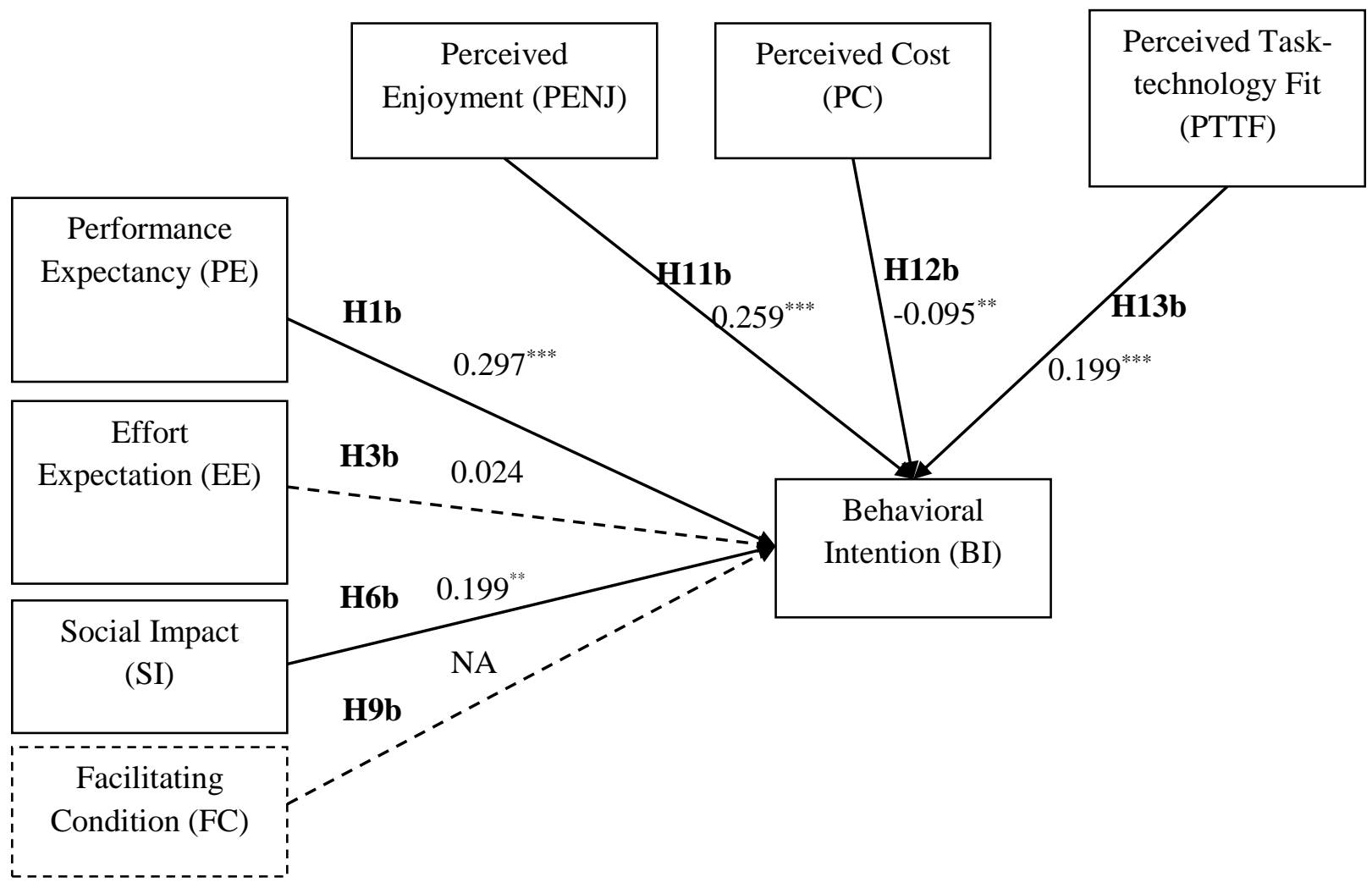

Figure 3. Path analysis of inexperienced users.

\section{Testing of Moderating Effects}

This study tested the effects of moderating variables (i.e., gender and experience) on the impacts of the four independent variables (PE, EE, SI, and FC) on BI, based on two levels of hierarchical regression analysis. Judging the existence of a moderating effect depends on the cross-multiplication p-value of the independent variable and moderating variable in the second-level hierarchical regression analysis, for which the p-value must be higher than 0.05 ( $p>0.05)$.

For the experienced participants, the standardized regression coefficients ( $\beta$ values) of the crossmultiplication of gender and the observed variable values are all insignificant (Gender $\mathrm{x}$ PE: $\beta=0.071 ; \mathrm{p}=$ 0.642; Gender x EE: $\beta=-0.177 ; p=0.256$; Gender $x$ SI: $\beta=0.024 ; p=0.914$ ). This means that gender is not the moderating factor in the proposed model for experienced users. By contrast, for inexperienced participants, the standardized regression coefficients ( $\beta$ values) of the cross-multiplication of gender and 
the observed variable values are all significant (Gender $x$ PE: $\beta=0.295 ; \mathrm{p}=0.015$; Gender $\times$ SI: $\beta=0.431$; $\mathrm{p}=0.023$ ), except for the EE variable (Gender $\mathrm{xEE}: \beta=0.018 ; \mathrm{p}=0.894$ ). These results indicate that gender is the moderating factor in the hypothesized model for inexperienced users, except for the influential path from EE to BI.

As the authors mentioned above, for inexperienced participants, gender is the moderating factor for two influential paths: From PE to BI and from SI to BI. This study further explored for which gender PE and SI produced the highest impact on BI by conducting a series of post hoc tests. In terms of the impact from PE to BI, the standardized regression coefficients ( $\beta$ values) of the gender's effect are 0.625 (male) and 0.738 (female), with $\mathrm{p}=0.000<0.001$, thereby reaching a significance level. Since both $\beta$ values are positive (female > male), PE has a positive impact on the students' BI toward using e-textbooks, with gender being a definite influence.

In terms of the impact from SI to $\mathrm{BI}$, the results show that the standardized regression coefficients ( $\beta$ values) of the gender effect are 0.464 (male) and 0.523 (female), with $\mathrm{p}=0.000<0.001$, thus reaching a significance level. Since both the $\beta$ values are positive (female $>$ male), this data indicate that SI has a positive impact on students' BI, with gender again having a definite effect.

Apart from gender effect, the questionnaires acquired from experienced users were utilized for testing the moderating effects of the experience variable on the hypothesized paths. As a result, the moderating effect of experience was found to be significant for the path of EE and BI (Experience $\mathrm{x}$ EE: $\beta=0.094 ; \mathrm{p}=0.041$ ). However, the moderating effects of experience are insignificant for the paths of SI and BI, and FC and BI (Experience $\mathrm{x}$ SI: $\beta=-0.012 ; \mathrm{p}=0.804$; Experience $\mathrm{xC}: \beta=0.027 ; \mathrm{p}=0.569$ ).

Accordingly, for the experienced participants, experience appears to be the moderating factor for the influential path of EE to BI. Thus, this study further explored which level of experience (high, medium, or low) produced the highest impact. As a result, the standardized regression coefficients ( $\beta$ values) of the effect of experience were 0.337 (low), 0.433 (medium), and 0.599 (high), with $p=0.000<0.001$, thereby reaching a significance level of 0.05. Since all $\beta$ values are positive (high $>$ medium $>$ low), EE has a positive impact on students' BI, with different levels of experience affecting the use intention. For students with high, medium, and low levels of experience, the explanatory power of EE to predict BI accounts for $35.9 \%, 18.7 \%$, and $11.4 \%$ of the variance, respectively.

In summary, Table 2 provides the results for testing the direct and moderating effects as the authors hypothesized. If the result of the path is significant, it is denoted with "Yes". 
Table 2

\section{Results of Hypotheses Testing}

\begin{tabular}{crcc}
\hline Hypotheses & Path & $\begin{array}{c}\text { Experienced users } \\
\text { significant? }\end{array}$ & $\begin{array}{c}\text { Inexperienced users } \\
\text { significant? }\end{array}$ \\
\hline $\mathrm{H} 1$ & $\mathrm{PE} \rightarrow \mathrm{BI}$ & Yes & Yes \\
$\mathrm{H} 3$ & $\mathrm{EE} \rightarrow \mathrm{BI}$ & No & No \\
$\mathrm{H} 6$ & $\mathrm{SI} \rightarrow \mathrm{BI}$ & No & Yes \\
$\mathrm{H} 9$ & $\mathrm{FC} \rightarrow \mathrm{BI}$ & Yes & NA \\
$\mathrm{H} 11$ & $\mathrm{PENJ} \rightarrow \mathrm{BI}$ & Yes & Yes \\
$\mathrm{H} 12$ & $\mathrm{PC} \rightarrow \mathrm{BI}$ & No & Yes, but negative \\
$\mathrm{H} 13$ & $\mathrm{PTTF} \rightarrow \mathrm{BI}$ & Yes & Yes \\
\hline $\mathrm{H} 2$ & Gender $\bmod (\mathrm{PE} \rightarrow \mathrm{BI})$ & No & Yes \\
$\mathrm{H} 4$ & Gender $\bmod (\mathrm{EE} \rightarrow \mathrm{BI})$ & No & No \\
$\mathrm{H} 7$ & Gender $\bmod (\mathrm{SI} \rightarrow \mathrm{BI})$ & No & Yes \\
\hline $\mathrm{H} 5$ & Experience $\bmod (\mathrm{PE} \rightarrow \mathrm{BI})$ & Yes & NA \\
$\mathrm{H} 8$ & Experience $\bmod (\mathrm{SI} \rightarrow \mathrm{BI})$ & No & NA \\
$\mathrm{H} 10$ & Experience $\bmod (\mathrm{FC} \rightarrow \mathrm{BI})$ & No & NA \\
\hline
\end{tabular}

\section{Discussions of Direct Effects}

For both experienced and inexperienced users, PE has a positive impact on BI. This finding agrees with prior studies of technology acceptance, which contend that people accept technology through a belief that it is useful for improving their performance and efficiency in certain tasks (Agarwal \& Karahanna, 2000; Fishbein \& Ajzen, 1975; Karahanna, Straub, \& Chervany, 1999).

In both usage models, EE has a positive, but insignificant impact on tertiary students' BI. However, this result differs from prior studies suggesting that EE should have a significant impact on BI. In this study, the insignificant impact may be due to e-textbooks requiring fundamental IT skills, rather than advance or high-level ones.

For tertiary students with experience of using e-textbooks, SI bears no significance for their BI. Contrarily, for those without experience using textbooks, SI has a positive impact on students' BI. The results imply that students may be influenced by others prior to gaining experience of using e-textbooks. Differing from 
the assumptions in the previous literature, after using e-textbooks, the opinions of others seem to be no longer influencing tertiary students' acceptance.

Venkatesh et al. (2003) suggested that FC does not affect BI; however, this study found that FC does have a significant impact on tertiary students' BI, albeit only in the experienced-student model. This implies that assistance from external sources does not influence the adoption intention of inexperienced users. Perhaps without experience of using e-textbook, users do not understand how these facilitations could be helpful in adopting the technology. After using it, however, and with the availability of external resources, tertiary students BI towards use increases.

PENJ has a positive and significant impact on tertiary students' BI for both usage models, which is in line with Venkatesh et al. (2003). E-textbooks provide students with a new form of learning and reading that allows them to remain in their own personal space and use interactive methods for studying in new and challenging ways. If students achieve greater enjoyment during the learning process, the sense of frustration with the difficulty of learning declines, and may in turn increase the willingness to use etextbooks.

For the experienced students, PC bears no significant impact on their BI. The reason for this may be that e-textbooks remain in an early stage of promotion in Taiwanese tertiary institutions, and students can browse and read e-textbooks in Portable Document Format (PDF) without much additional cost as long as the displaying device has Adobe Reader installed. Contrarily, for those without experience, PC has a significant but negative impact among tertiary students' BI. These results may be due to their impressions that the use of e-textbooks incurs costs for purchasing hardware, accessing networks, and other expenses.

PTTF has a positive impact on tertiary students' BI in both models (with and without experience), which is consistent with Goodhue and Thompson (1995). This indicates that, when the e-textbook and its functions are compatible with students' learning styles and learning tasks, they tend to use it. Tertiary students are frequently required to prepare various kinds of written reports. In order to assist these complicated tasks and materials, e-textbooks provide advantages over traditional textbooks, such as keyword searches, built-in dictionaries, cross-references, and even interactive maps and charts. Moreover, these technical functions can meet the demands of tertiary students' learning tasks, and can, therefore, increase their willingness to use them.

\section{Discussions of Moderating Effects}

As Table 2 shows, gender has no moderating effect on the hypothesized interrelationships in the model of experienced users. However, for inexperienced female users, gender has a moderating effect on the hypothesized interrelationships between PE, SI, and BI. It seems that SI via recommendations from friends, newspapers, and magazines are more influential to female students than to males, when students expect e-textbooks to enhance their learning efficiency. Among experienced tertiary students, the level of experience moderates the relationship between EE and BI, indicating that the amount of effort required to use e-textbooks is more of a concern for experienced users. However, the level of experience does not 
moderate the impacts of SI or FC on BI. Perhaps, the use of e-textbooks may be influenced by other strong environmental factors, such as university policy and incentives.

\section{Conclusion}

This study discovered several critical factors in the UTAUT, the PTTF, and the PENJ models, which may help students accept e-textbooks. Several factors have rarely been discussed in the prior literature about e-textbooks. As such, findings from this study can serve as a guide for studying e-textbook acceptance in the future. Moreover, this study also found that both gender and usage experience influence the acceptance models of both experienced and inexperienced users of the technology.

Comparing the adoption models between experienced and inexperienced users, the great differences lie in whether social impact, facilitating condition, and perceived cost contribute significant influence on BI. In terms of social impact for experienced users, students tend to use e-textbooks based on their habits and learning styles, irrespective of peer influence. However, in the case of inexperienced users, friends and classmates can be influential to their intention of using e-textbooks. In terms of facilitating condition and perceived cost for inexperienced tertiary students, supportive resources from the institution would not affect their intention toward using e-textbooks, and they are concerned about using the technology due to costs. However, after actual usage, experienced students may discover that e-textbooks do not require much extra cost for continuous use, perhaps only networking fees. Experienced students also expect more supportive resources. As such, it is suggested that tertiary institutions provide resources, such as training tutorials, to resolve the difficulties and obstacles that may be encountered when using e-textbooks.

Regarding the moderating effects, gender does not induce any moderating effect in the proposed acceptance model, while experience can moderate the relationship between effort expectation and BI. Further, gender has moderating effects on the hypothesized interrelationships between PE, social impact, and BI for inexperienced users, and the effect is particularly high in the case of females. These findings indicate that female students' perception toward using e-textbooks to enhance learning efficiency is higher than male students. Also, for female students, the influence of friends' experiences and recommendations from newspapers and magazines are stronger than for males.

For practical implications, this study found that FC will affect experienced users' willingness to use etextbooks. Therefore, if Taiwanese colleges and universities wish to promote the use of e-textbooks effectively, they should develop a long-term facilitating mechanism to support students in utilizing etextbooks for learning. In a real world scenario, this study suggests that lecturers may play a mediating or supervisory role to guide students' use of e-textbooks during lectures. It is also possible to offer pre-class and after-class support during the processes of adoption for learning. Moreover, since the value chain in the textbook industry includes students, lecturers, and publishers, satisfying the needs of these three parties is necessary in the promotion of e-textbooks. Yet, the existing literature only focused on aspects associated with the industry's value chains and lecturers, and lacks student-related research. Hopefully, 
this study provided useful guidelines for marketing strategies on e-textbooks, and thus filled the literature gap.

Apparently, using e-textbooks for learning has become an efficient way to acquire knowledge, particularly in the scenarios of distributed and open learning. People can use e-textbooks to gain knowledge at any time and any place as long as the electronic reader is available. The factor of social impact has significant influence on inexperienced users' acceptance intention, which means that creating a strong social environment for the students and their social entities can stimulate the use of e-textbooks and thus shape an interactive and better distributed learning environment.

This study has several limitations and foresees future directions for research. First, the theoretical model of this study is focused on intention and tertiary students' feelings toward e-textbooks. Consequently, caution is necessary when interpreting the authors' results in order to predict actual behavior toward using e-textbooks in other contexts. Second, the participants in this study represented a selection of tertiary students without specifically targeting any department. Therefore, future research might focus on tertiary students in specific disciplines, such as science or liberal arts majors, to study the differences toward using e-textbooks among students of different fields. The differences among departments and the reasons for those differences could deepen our understanding of the use of technology. Third, after etextbooks become more common, future research could test the factors in this study on their influences toward continuous use of e-textbooks. 


\section{References}

Agarwal, R., \& Prasad, J. (1997). The role of innovation characteristics and perceived voluntariness in the acceptance of information technologies. Decision Sciences, 28(3), 557-582.

Agarwal, R., \& Karahanna, E. (2000). Time flies when you're having fun: Cognitive absorption and beliefs about information technology usage. MIS Quarterly, 24(4), 665-694.

Al-Ali, S., \& Ahmed, A. (2015). E-textbooks in ESL classrooms: Are learners on board? Learning and Teaching in Higher Education: Gulf Perspectives, 12(2). Retrieved from http://lthe.zu.ac.ae/index.php/lthehome/issue/view/13

Amoroso, D. L., \& Hunsinger, D. S. (2009). Understanding consumers' acceptance of online purchasing. Journal of Information Technology Management, 1O(1), 15-41.

Baker, E. W., Al-Gahtani, S. S., \& Hubona, G. S. (2010). Cultural impacts on acceptance and adoption of information technology in a developing country. Journal of Global Information Management, 18(3), 35-58.

Boroughs, D. (2010, April). Bye the book: In educational publishing, the only certainty is change. Retrieved from http://www.prism-magazine.org/apr10/feature 01.cfm

Bruner II, G. C., \& Kumar, A. (2005). Explaining consumer acceptance of handheld internet devices. Journal of Business Research, 58(5), 553-558.

Chen, P. Y., \& Hitt, L. M. (2002). Measuring switching costs and the determinants of customer retention in Internet-enabled businesses: A study of the online brokerage industry. Information Systems Research, 13(30), 255-274.

Chung, J., \& Tan, F. B. (2004). Antecedents of perceived playfulness: An exploratory study on user acceptance of general information-searching websites. Information \& Management, 41(7), 869881.

Clough, G., Jones, A. C., McAndrew, P., \& Scanlon, E. (2008). Informal learning with PDAs and smartphones. Journal of Computer Assisted Learning, 24(5), 359-371.

Dasgupta, S., Haddad, M., Weiss, P., \& Bermudez, E. (2007). User acceptance of CASE tools in systems analysis and design: An empirical study. Journal of Informatics Education Research, 9(1), 51-78.

Davis, F. D. (1989). Perceived usefulness, perceived ease of use, and user acceptance of information technology. MIS Quarterly, 13(3), 319-339.

Davis, F. D., Bagozzi, R. P., \& Warshaw, P. R. (1992). Extrinsic and intrinsic motivation to use computers 
in the workplace. Journal of Applied Social Psychology, 22(1), 1111-1132.

Dennis, A. R., Abaci, S., Morrone, A. S., Plaskoff, J., \& McNamara, K. (2016). Effects of e-textbook instructor annotations on learner performance. Journal of Computing in Higher Education, 28(2), 221-235.

Fischer, L., Hilton, J., Robinson, T. J., \& Wiley, D. A. (2015). A multi-institutional study of the impact of open textbook adoption on the learning outcomes of post-secondary students. Journal of Computing in Higher Education, 27(3), 159-172.

Fishbein, M., \& Ajzen, I. (1975). Belief, attitude, intention, and behavior: An introduction to theory and research. Reading, MA: Addison-Wesley Pub. Co.

Gerhart, N., Peak, D., \& Prybutok, V. (2015). Searching for new answers: The application of tasktechnology fit to e-textbook usage. Decision Sciences Journal of Innovative Education, 13(1), 91111.

Goodhue, D. L., \& Thompson, R. L. (1995). Task-technology fit and individual performance. MIS Quarterly, 19(1), 213-236.

Gu, X., Wu, B., \& Xu, X. (2015). Design, development, and learning in e-Textbooks: What we learned and where we are going. Journal of Computers in Education, 2(1), 25-41.

Gurung, R. A. R., \& Daniel, D. (2005). Do text-based pedagogical features enhance student learning? In D. S. Dunn, \& S. L. Chew (Eds.), Best practices for teaching introduction to psychology (pp. 41-55). New Jersey: Lawrence Erlbaum.

Hair, J. F., Black, W. C., Babin, B. J., \& Anderson, R. E. (2010). Multivariate data analysis - A global perspective. New Jersey: Pearson Education.

Harrison, D. A., Mykytyn, P. P., \& Riemenschneider, C. K. (1997). Executive decisions about adoption of information technology in small business: Theory and empirical tests. Information Systems Research, 8(2), 171-195.

Hsiao, C. H., Tang, K. Y., \& Lin, C. H. (2015). Exploring college students' intention to adopt e-textbooks: A modified technology acceptance model. Libri, 65(2), 119-128.

Isa, S. M., \& Wong, K. Y. (2015). Age differences in behavioral intention to use internet marketing: A comparative study between Malaysian and Taiwanese. International Journal of Business \& Society, 16(3), 386-396.

Johnston, D., Berg, S., Pillon, K., \& Williams, M. (2015). Ease of use and usefulness as measures of student experience in a multi-platform e-textbook pilot. Library Hi Tech, 33(1), 65-82. 
Kaba, B., \& Touré, B. (2014). Understanding information and communication technology behavioral intention to use: Applying the UTAUT model to social networking site adoption by young people in a least developed country. Journal of the Association for Information Science \& Technology, 65(8), 1662-1674.

Karahanna, E., Straub, D. W., \& Chervany, N. L. (1999). Information technology adoption across time: A cross-sectional comparison of pre-adoption and post-adoption beliefs. MIS Quarterly, 23(2), 183213 .

Kohnke, A., Cole, M., \& Bush, R. (2014). Incorporating UTAUT predictors for understanding home care patients' and clinician's acceptance of healthcare telemedicine equipment. Journal of Technology Management \& Innovation, 9(2), 29-41.

Kuo, R. Z. (2011). Knowledge management system adoption: Exploring the effects of empowering leadership, task-technology fit and compatibility. Behaviour \& Information Technology, 3o(1), 113-129.

Lai, J. Y., \& Ulhas, K. R. (2012). Understanding acceptance of dedicated e-textbook applications for learning: Involving Taiwanese university students. The Electronic Library, 3o(3), 321-338.

Lee, M. K. O., Cheung, C. M. K., \& Chen, Z. (2005). Acceptance of Internet-based learning medium: The role of extrinsic and intrinsic motivation. Information \& Management, 42(8), 1095-1104.

Lin, T. C., \& Huang, C. C. (2008). Understanding knowledge management system usage antecedents: An integration of social cognitive theory and task technology fit. Information \& Management, 45(6), 410-417.

Liu, W. Y., \& Tsai, C. H. (2011). An application of the UTAUT model for understanding learning management systems adoption of college teachers. Journal of Performance and Strategy Research, 8(2), 49-60.

Marcolin, B. L., Compeau, D. R., Munro, M. C., \& Huff, S. L. (2000). Assessing user competence: Conceptualization and measurement. Information Systems Research, 11(1), 37-60.

Mathieson, K. (1991). Predicting user intentions: Comparing the technology acceptance model with the theory of planned behavior. Information Systems Research, 2(3), 173-191.

Maynard, S., \& Cheyne, E. (2005). Can electronic textbooks help children to learn? The Electronic Library, 23(1), 103-115.

Moon, J. W., \& Kim, Y. G. (2001). Extending the TAM for a world-wide web context. Information \& Management, 38(1), 217-230. 
Moore, G. C., \& Benbasat, I. (1991). Development of an instrument to measure the perceptions of adopting an information technology innovation. Information Systems Research, 2(3), 192-222.

Ngafeeson, M. N., \& Sun, J. (2015). The effects of technology innovativeness and system exposure on student acceptance of e-textbooks. Journal of Information Technology Education: Research, 14, $55^{-71 .}$

Pai, J. C., \& Tu, F. M. (2011). The acceptance and use of customer relationship management (CRM) systems: An empirical study of distribution service industry in Taiwan. Expert Systems with Applications, 38(1), 579-584.

Shin, S., Chung, N., Hart, R. J., Joun, Y., \& Koo, C. (2015). Examining technology perception and user competence on two types of smartphone usages. In Proceedings of the Pacific Asia Conference on Information Systems (PACIS) 2015 (p. 105). Retrieved from http://aisel.aisnet.org/pacis2015/105/

Stone, R. W., \& Baker-Eveleth, L. (2013). Students' expectation, confirmation, and continuance intention to use electronic textbooks. Computers in Human Behavior, 29(3), 984-990.

Szajna, B. (1996). Empirical evaluation of the revised technology acceptance model. Management Science, 42(1), 85-92.

Thompson, R. L., Higgins, C. A., \& Howell, J. M. (1991). Personal computing: Toward a conceptual model of utilization. MIS Quarterly, 15(1), 124-143.

Van der Heijden, H. (2004). User acceptance of hedonic information systems. MIS Quarterly, 28(4), 695704.

Venkatesh, V., Brown, S. A., Maruping, L. M., \& Bala, H. (2008). Predicting different conceptualizations of system use: The competing roles of behavioral intention, facilitating conditions, and behavioral expectation. MIS Quarterly, 32(3), 483-502.

Venkatesh, V., \& Davis, F. D. (2000). A theoretical extension of the technology acceptance model: Four longitudinal field studies. Management Science, 46(2), 186-204.

Venkatesh, V., \& Morris, M. G. (2000). Why don’t men ever stop to ask for directions? Gender, social influence, and their role in technology acceptance and usage behavior. MIS Quarterly, 24(1), 115139 .

Venkatesh,V., Morris, M. G., \& Ackerman, P. L. (2000). A longitudinal field investigation of gender differences in individual technology adoption decision making processes. Organizational Behavior and Human Decision Processes, 83(1), 33-60. 
Venkatesh, V., Morris, M. G., Davis, G. B., \& Davis, F. D. (2003). User acceptance of information technology: Toward a unified view. MIS Quarterly, 27(1), 425-478.

Venkatesh, V., Thong, J. Y. L., \& Xu, X. (2012). Consumer acceptance and use of information technology: Extending the unified theory of acceptance and use of technology. MIS Quarterly, 36(1), 157-178.

Vessey, I. (1991). Cognitive fit: A theory-based analysis of the graphs versus tables literature. Decision Sciences, 22(2), 219-240.

Wang, H. I., \& Yang, H. L. (2005). The role of personality traits in UTAUT model under online stocking. Contemporary Management Research, 1(1), 69-82.

Woody, W. D., Daniel, D. B., \& Baker, C. A. (2010). E-books or textbooks: Students prefer textbooks. Computers \& Education, 55(3), 945-948.

Wu, J. H., \& Wang, S. C. (2005). What drives mobile commerce? An empirical evaluation of the revised technology acceptance model. Information \& Management, 42(5), 719-729.

Young, J. R. (2001). A university that reveres tradition experiments with e-books. The Chronicle of Higher Education, 47(36), 35-46.

Zhou, T., Lu, Y., \& Wang, B. (2010). Integrating TTF and UTAUT to explain mobile banking user adoption. Computers in Human Behavior, 26(4), 760-767.

\section{Athabasca University}

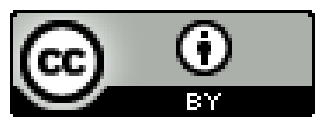

